\title{
ЗДОРОВЬЕ ДЕТЕЙ ШКОЛЬНОГО ВОЗРАСТА: ФАКТОРЫ РИСКА
}

\section{И.Н. Разварина}

(https://orcid.org/0000-0002-9377-1829),

\author{
М.А. Груздева \\ (https://orcid.org/0000-0001-8759-4953)
}

\section{Вологодский научный изентр Российской академии наук, Вологда, Россия} e-mail:irina.razvarina@mail.ru,mariya_antonovarsa@mail.ru

\section{DOI: 10.14258/ssi(2019)4-10}

Представлены результаты изучения поведенческих факторов риска здоровья детей в Вологодской области. На основе комплексной оценки родителями, детьми, специалистами школы выявлены проблемные зоны формирования здоровья обучающихся в образовательных организациях г. Вологды и г. Череповца. Полученные результаты позволили акцентировать внимание на ряде аспектов практической и теоретической деятельности по охране здоровья детей, сформировать научно-методическую базу для обоснования развития системы охраны здоровья детей школьного возраста в Вологодской области.

Ключевые слова: детское здоровье, поведенческие факторы, здоровьесберегающая деятельность.

\section{SCHOOL-AGE CHILDREN'S HEALTH: RISK FACTORS}

\section{I.N. Razvarina, M.A. Gruzdeva \\ Vologodskiy Scientific Center of the Russian Academy of Sciences, Vologda, Russia, e-mail: irina.razvarina@mail.ru,mariya_antonovarsa@mail.ru}

The paper presents the results of a study of behavioral risk factors for children's health in the Vologda Oblast. On the basis of a comprehensive assessment by parents, children, and school specialists, problem zones of students' health formation were identified in the educational institutions of Vologda and Cherepovets. The results obtained made it possible to focus on a number of aspects of practical and theoretical activities for the health of students, to form a scientific and methodological basis - identifying risk factors for children to justify the development of a health system for school-age children in the Vologda Oblast.

Keywords: children's health, behavioral factors, health-saving activities. 


\section{Введение}

Здоровье является одной из важных характеристик детства. Оно закладывается с ранних лет и определяет личностный рост и возможности социально-трудовой активности человека (Шабунова и др., 2014).

Изучению детского здоровья посвящены многочисленные работы отечественных и зарубежных ученых. Наиболее авторитетными исследователями данной темы в России являются А. Баранов, Г. Вельтищев, И. Веселкова, Е. Бреева, С. Громбарх, Н.М. Римашевская, А.А. Шабунова. Среди зарубежных работ интерес представляет работа британских ученых Национального института детства (NCB) и Центра многолетних исследований (CLS), которые уже более 50 лет занимаются долгосрочным изучением детского здоровья. Результаты выявили факторы, влияющие не только на здоровье, но и на другие показатели развития детей (Jane Elliott, Romesh Vaitilingam, 2008).

На заседании Координационного совета по реализации «Национальной стратегии действий в интересах детей» Президент РФ обозначил ряд наиболее приоритетных в данной области вопросов и подчеркнул, что «сохранение и укрепление здоровья детей требуют комплексного, межведомственного подхода на всех уровнях власти...». Наиболее выраженное ухудшение здоровья происходит в период получения образования. К выпускному классу школы частота функциональных нарушений возрастает на 86\%, хронических болезней — на 100\%. Наблюдаются устойчивые негативные тенденции в состоянии здоровья детей, характеризующиеся высоким уровнем заболеваемости (в стране около $35 \%$ детей уже рождаются больными). Поэтому наряду с необходимостью укрепления детского здоровья важным является формирование у детей не только понимания, но и осознания необходимости здорового образа жизни с раннего возраста (Кононова, 2016).

В Вологодской области за период с 2008 по 2017 г. наблюдалась неравномерная динамика значений относительного показателя общей заболеваемости детей в возрасте 0-17 лет. В целом отмечается рост относительного показателя общей заболеваемости детей на 7\%. В связи с этим актуализируются проблемы профилактики заболеваний детей и наряду с необходимостью укрепления детского здоровья важным является формирование у детей не только понимания, но и осознания необходимости ведения здорового образа жизни с раннего возраста (Вельтищев, 2000).

Особое внимание обратим на подростковый период детства (с 10 до 17 лет), он характеризуется снижением показателей здоровья по сравнению с младшим школьным возрастом и отличается от более ранних этапов жизни ребенка тем, что характеризуется рассогласованностью физического и психического развития (Разварина, 2016). Зачастую дети не готовы к тому, что в организме происходят физиологические изменения, которые могут отразиться на поведении. Особые сложности для ребенка связаны с необходимостью преодолевать возрастающую учебную нагрузку на фоне ослабления внимания родителей к проблемам воспитания и обучения (Шабунова, Кондакова, 2014). Эти факторы могут негативно влиять на состояние физического и психического здоровья подростков, провоцировать рискованные и саморазрушительные формы поведения (Шац, 2010; Эйдемиллер, 2015). 
Объект исследования: семьи с детьми в возрасте от 7 до 17 лет, проживающие на территории Вологодской области.

Цель: выявление поведенческих факторов риска здоровья детей школьного возраста.

\section{Методология исследования и информационная база}

Информационной базой исследования выступили данные официальной статистики и социологическая информация.

В работе использованы результаты исследования по теме «Факторы здоровья детей школьного возраста на примере г. Вологды и г. Череповца», выполненного в 2016 г. специалистами ВолНЦ РАН, в рамках договора с Медицинским информационно-аналитическим центром Вологодской области. Исследование включало социологический опрос родителей школьников (1200 чел.), детей, а также изучение мнений педагогов и администрации школ в рамках формализованного интервью. Для каждого из приоритетных классов заболеваний были составлены перечни факторов риска, действующих на здоровье в семье и в школе, родителям было предложено оценить свою роль, роль школы, наследственности в их формировании.

\section{Результаты и обсуждение}

В результате исследования было выявлено, что старшеклассники имеют худшее здоровье по сравнению с первоклассниками. Так, хронические болезни органов зрения выявлены у 9\% первоклассников. К 11-му классу доля таких детей возрастает до $34 \%$. Аналогичная картина наблюдается по заболеваниям опорно-двигательного аппарата: в 1-м классе - 7\% детей, в 11-м классе - 17\%. Анализ результатов позволил предположить также, что родители не чувствуют своей ответственности за ухудшение здоровья детей: проявляют склонность оставлять этот вопрос без ответа (от $34 \%$ до 60\% ответов по разным классам заболеваний) или указывать в качестве вероятной причины действие неуправляемого (генетического) фактора. Доля родителей, признающих собственную ответственность за ухудшение здоровья ребенка, не превышает 7\%.

Установлено, что родители недостаточно информированы о состоянии здоровья детей, поскольку наблюдаются расхождения между высказанными ими оценками здоровья детей и диагнозами, отраженными в медицинских картах последних, которые изучались в ходе исследования. Например, наличие хронических заболеваний опорно-двигательного аппарата у детей отметили только $11 \%$ родителей, тогда как по документальным сведениям эти нарушения здоровья присутствуют у $35 \%$ детей.

Число поведенческих факторов, влияющих на здоровье ребенка, растет по мере его взросления: так, на здоровье первоклассников влияет меньшее количество поведенческих факторов, чем у обучающихся 11 классов. В начальных классах более выражен контроль родителей. На первое место в старшей школе выходит поведение самого ребенка, у старшеклассников (10-11 класс) слабо сформированы навыки самоконтроля в сфере здоровьесбережения. И воспитательное воздействие родителей также по мере взросления становится более непоследовательным. 
Есть расхождения между детьми и родителями в оценках проблем со здоровьем. Так, ученики 11 класса чаще, чем их родители, выбрали ответ, что имеют проблемы со зрением (44\% против 34\%), опорно-двигательным аппаратом, осанкой (45\% против 17\%). Девятиклассники по сравнению с родителями также чаще отмечали проблемы со зрением (37\% против 29\%), функционированием опорно-двигательного аппарата (35\% против 15\%).

По ответам родителей можно сделать вывод, что они переносят ответственность на школу по профилактике заболеваний опорно-двигательного аппарата, таких как систематический контроль осанки, посещение занятий ЛФК (лечебная физкультура), профилактика травматизма. Также они отмечают слабую коммуникацию по вопросам охраны здоровья детей между ними и образовательной организацией. Тем не менее такое взаимодействие необходимо для организации здоровьесберегающей среды в образовательной организации.

Помимо изучения мнения родителей был проведен анализ программ здоровьесбережения, принятых в городах Вологда и Череповец, который показал, что они не полностью обеспечивают комплексность охраны здоровья детей. Так, ни в одной из рассмотренных программ других образовательных организаций не затрагивается элемент охраны здоровья педагогического персонала, не уделяется должного внимания и прочим компонентам. Вместе с тем зарубежный опыт показывает возможность и эффективность подобных программ, в частности восьмикомпонентной модели комплексной программы школьного здоровья (Coordinated School Health, SHC). Родители также дают низкие оценки реализации различных компонентов здоровьесбережения, таких как благоприятный психологический климат, обучение физическим навыкам, деятельность различных школьных служб: медицинской, консультационной, психологической, социальной, организации питания. Самые низкие оценки получили наличие специальной образовательной программы и охрана здоровья педагогов (только $14 \%$ и $12 \%$ родителей оценивают их положительно). Примечательно, что в целом родителям крайне сложно оценить состояние каждого из компонентов системы здоровьесбережения: в школе доли затрудняющихся с оценкой составили от 30 до $60 \%$, что свидетельствует не только о том, что родители не берутся объективно оценивать состояние основных элементов здоровьесбережения в школах, в которых учатся их дети, но и демонстрируют низкую осведомленность в данных вопросах.

Выявлены проблемы при организации контроля выполнения родителями рекомендаций, полученных в рамках диспансеризации детей. Установлено, что школы не в состоянии обеспечить удовлетворение потребностей детей, нуждающихся в занятиях лечебной физкультурой. Директора и заместители директоров школ, педагоги в рамках интервьюирования подчеркнули важность как физического, так и нервно-психического состояния ребенка. Выделили необходимость спортивной подготовленности, сформированности нравственных качеств, которые, так же как и духовность, играют важную роль в достижении успеха. Были приведены примеры, когда проблемы со здоровьем мешали в достижении профессионального успеха. Сами обучающиеся выпускных классов отмечали, что для людей с ограниченными 
возможностями здоровья возможна успешная социализация, однако для этого им необходимо приложить больше усилий, чем здоровому человеку.

\section{Заключение}

На основании проведенного исследования специалистами ВолНЦ РАН разработан проект Концепции здоровьесбережения средней общеобразовательной школы №13 города Вологда до 2022 г. Она основана на организации межведомственного взаимодействия с целью охраны психологического, социального и физического здоровья детей. При разработке программы особое внимание уделяется внутренним связям в школе, которые становятся основой для организации системы взаимодействия. Концепция здоровьесбережения в школе построена на основе восьмикомпонентной модели комплексной программы школьного здоровья. Она включает в себя: образование в области здоровья, физическое воспитание, работу школьной медицинской службы, работу службы питания, службы здоровья персонала школы, консультационной, психологической и социальной служб, здоровую среду школы, вовлечение родителей и общественности в деятельность по улучшению здоровья обучающихся. На основе данных компонентов формируется модель работы школы, обеспечивающая среду для сохранения и укрепления здоровья всех участников образовательного процесса на основе восьмикомпонентной модели комплексной программы школьного здоровья (Coordinated School Health, SHC); подтверждена необходимость введения в школах должности специалиста по здоровьесберегающей политике в образовательной организации.

Проведенный анализ позволил сформулировать направления развития политики здоровьесбережения в образовательных организациях на основе эффективного взаимодействия с детьми и их родителями, профилактики нарушений формирования личностных качеств у ребенка. Сделан важный вывод о необходимости использования адаптационного подхода в здоровьесберегающей деятельности в образовательных организациях (Разварина, 2017). Он базируется на применении механизма внутриведомственного и межведомственного взаимодействия образовательных и медицинских организаций на доврачебном этапе оценки нервно-психического развития в части разработки алгоритма предоставления сведений о ребенке.

\section{БИБЛИОГРАФИЧЕСКИЙ СПИСОК}

Вельтищев Ю.Е. Проблемы охраны здоровья детей России. Российский вестник перинатологии и педиатрии, 2000, No. 1, 59.

Шабунова А.А. Здоровье и здравоохранение: учебное пособие. Вологда: ИСЭРТ PAH, 2014.

Кононова А.Е. Социально-экономические факторы детского здоровья в России. Социологические исследования, 2016, No. 4, 94-102.

Разварина И.Н. Здоровье как фактор формирования личностных качеств подростков. Вопросы территориального развития, 2016, No. 3.

Разварина И.Н. Адаптационный подход к оценке нервно-психического развития де- 
тей младшего школьного возраста: методические рекомендации для педагогов-психологов, социальных педагогов и классных руководителей общеобразовательных организаций. Вологда, ИСЭРТ РАН, 2017.

Шабунова А.А., Кондакова Н.А. Здоровье и развитие детей: итоги 20-летнего мониторинга. Экономические и социальные перемены: факты, тенденции, прогноз, 2014, No. 5, 33-54.

Шац И.К. Психологическая поддержка тяжелобольного ребенка. СПб.: Речь, 2010.

Эйдемиллер Э.Г. Клиническая психология и психотерапия семьи и детства: традиции и современность. Психическое здоровье, 2015, No. 2, 45-50.

Now we are 50: Key findings from the National Child Development Study. Edited by Jane Elliott and Romesh Vaitilingam. London, 2008.

\section{REFERENCES}

Veltishchev, Yu.E. (2000). Problemy okhrany zdorov'ya detej Rossii [Problems of protecting the health of children in Russia]. Rossijskij vestnik perinatologii i pediatrii [Bulletin of Perinatology and Pediatrics], no 1, 59-63.

Shabunova, A.A. (2014). Zdorov'e i zdravoohranenie: uchebnoe posobie [Health and healthcare: a textbook for universities]. Vologda: ISEDT RAS.

Kononova, A.E. (2016). Sotsialno-ekonomicheskie faktory detskogo zdorovia v Rossii [Socio-economic factors of children's health in Russia]. Sociologicheskie issledovaniya [Sociological studies], no 4, 94-102.

Razvarina, I.N. (2016). Zdorov'e kak faktor formirovaniya lichnostnyh kachestv podrostkov [Health as a factor in the formation of personal qualities of adolescents]. Voprosy territorial'nogo razvitiya [Issues of territorial development], no 3 (33). URL: http://vtr.isert-ran.ru/article/1892

Razvarina, I.N. (2017). Adaptatsionnyj podhod k ocenke nervno-psihicheskogo razvitiya detej mladshego shkol'nogo vozrasta: metodicheskie rekomendacii dlya pedagogov-psihologov, socialnyh pedagogov i klassnyh rukovoditelej obshcheobrazovatel'nyh organizacij [An adaptive approach to assessing the neuropsychic development of children of primary school age: methodological recommendations for educational psychologists, social educators, and class teachers of educational institutions]. Vologda, ISEDT RAS.

Shabunova, A.A., Kondakova, N.A. (2014). Zdorov'e i razvitie detej: itogi 20-letnego monitoringa [Children's health and development: results of a 20-year monitoring]. Ekonomicheskie i social'nye peremeny: fakty, tendencii, prognoz [Economic and social changes: facts, trends, forecast], no. 5 (35), 33-54.

Schatz, I.K. (2010). Psihologicheskaya podderzhka tyazhelobol'nogo rebenka [Psychological support for a seriously ill child]. St. Petersburg: Rech.

Eidemiller, E.G. (2015). Klinicheskaya psihologiya i psihoterapiya sem'i i detstva: tradicii i sovremennost' [Clinical psychology and psychotherapy of family and childhood: traditions and modernity]. Psihicheskoe zdorov'e [Mental Health], no 2, 45-50.

Now we are 50: Key findings from the National Child Development Study (2008). Edited by Jane Elliott and Romesh Vaitilingam. London. 